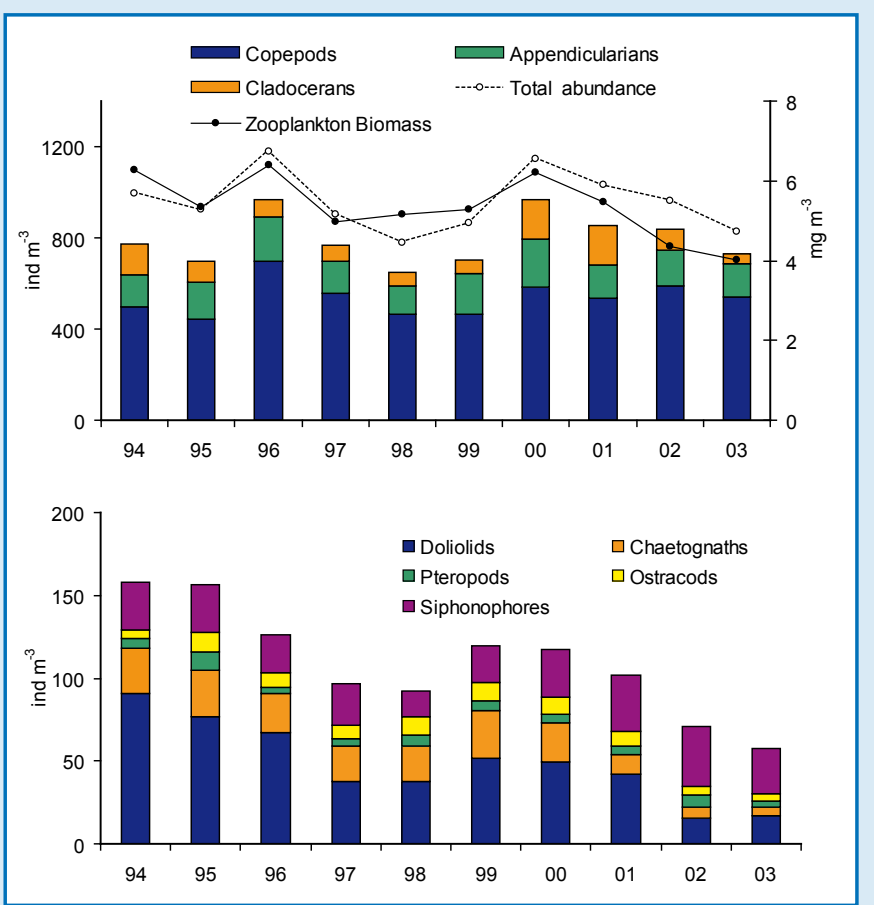

Figure 4. Interannual variability of main zooplankton groups (annual values of biomass as $\mathrm{mg} \mathrm{m}^{-3}$ and abundance as ind $\mathrm{m}^{-3}$ ).

to that, the Mallorca channel would be a sensitive area to study large scale effects in the western Mediterranean. The synchronous variation found between the abundance of zooplankton groups and the hydrological features in the Balearic Sea suggests strong linkages to mechanisms acting over large scales, likely related to atmospheric oscillations, as main drivers of the hydrodynamics at the scale of the western Mediterranean basin. Since temporal variability was observed during these 10 years of data, they seem not to be enough to draw final conclusions and, larger scale investigations should be conducted, especially to further determine the relationship between atmospheric oscillations and western Mediterranean zooplankton. This may help us to improve our knowledge and better comprehend the zooplankton variability in the pelagic ecosystems of temperate latitudes. In order to assess ecological mechanisms through which planktonic functional groups respond to hydrographic regimes driven by climate, future work should focus on the identified indicator zooplankton species at different time-scales as in other areas of the North Atlantic (Fromentin and Planque, 1996). In turn, in response to a warming climate, this will improve our ability to forecast future changes in the abundance and distribution of the zooplankton community in the whole Mediterranean Sea.

\section{References}

Christou E.D. 1998. Interannual variability of copepods in a Mediterranean coastal area (Aegean Sea). Journal Marine Systems 15: 523-532.

Estrada M., F. Vives and M. Alcaraz. 1985. Life and production in the open sea. p. 150-200. In: R. Margalef (Ed.). The western Mediterranean. Pergamon Press, London.

Fernandez de Puelles M.L., F. Alemany and J. Jansa. 2007. Zooplankton time-series in the Balearic Sea (western Mediterranean): Variability during the decade 1994-2003. Progress in Oceanography 74(2-3): 329-354.

Fromentin J.M. and B. Planque. 1996. Calanus and environment in the eastern north Atlantic. II. Influence of the north Atlantic oscillation on C. finmarchicus and C. helgolandicus. Marine Ecology Progress Series 134: 101-109.

Mazzocchi M.G. and M. Ribera d'Alcala. 1995. Recurrent patterns in zooplankton structure and succession in a variable coastal environment. ICES Journal Marine Science 52: 679-691.

Vignudelly S., G.P. Gasparini, M. Astraldi and M.E. Schiano. 1999. A possible influence of the North Atlantic Oscillation on the circulation of the Western Mediterranean. Geophysical Research Letters 26(5): 623-626

\title{
Physical and biological processes controlling the distribution of fish larvae in the NW Mediterranean

\author{
Ana Sabatés ${ }^{1}$ (anas@icm.csic.es), Maria Pilar Olivar ${ }^{1}$, Jordi Salat ${ }^{1}$, \\ Isabel Palomera ${ }^{1}$ and Francisco Alemany ${ }^{2}$
} \\ ${ }^{1}$ Institut de Ciències del Mar (CSIC), Barcelona, Spain \\ ${ }^{2}$ Instituto Español de Oceanografía Centro Oceanográfico de Baleares, Palma de Mallorca, Spain
}

The Mediterranean is globally considered to be an oligotrophic sea. However, its complex coastline and bathymetry, added to a strong seasonality, lead to a high environmental diversity at both regional and local scales. Among these diverse environments there are certain places or seasons in which mechanisms that enhance fertility may occur. These mechanisms and related processes are especially relevant when they take place during the period of larval development. This study analyses how environmental conditions occurring in the NW Mediterranean at local and seasonal scales contribute to determining the temporal and spatial patterns of fish reproductive activity in the region. This includes a description of the main physical and biological processes responsible for productivity in relation to the temporal and spatial distribution patterns of fish larvae, as well as how these processes control the population dynamics of fish larvae in the region. This coupling between environmental processes and fish reproductive success is a key factor for understanding the maintenance of fish populations in the Mediterranean Sea.

The structure of the bathymetry, bottom type, diversity of adult fish habitats, as well as mechanisms controlling the primary production in the region determine the location of spawning, whereas physical processes (e.g. shelf-slope density front and associated currents, continental water inflows, winter mixing, stratification of the water column) determine the final distribution patterns of fish eggs and larvae. High larval concentrations occur over the edge of the continental shelf in relation to the presence of the shelf-slope front associated to the Northern Current. However, this pattern is subject to considerable spatio-temporal variability, due to frontal mesoscale activity and mechanisms 


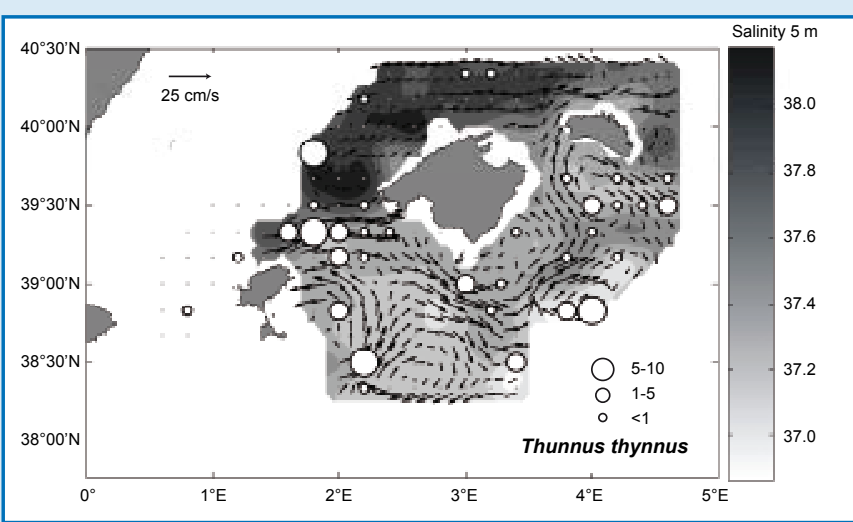

Figure 1. Distribution of Thunnus thynnus larvae off the Balearic archipelago. Larval fish abundance is expressed as number of individuals $/ 100 \mathrm{~m}^{3}$. Salinities under 37.8 correspond to waters of recent Atlantic origin. Arrows represent geostrophic currents at $10 \mathrm{~m}$ depth.

of convergence/accumulation and divergence/dispersion are associated with the current's meandering flow pattern (Sabatés et al., 2004). Larvae of large pelagic migratory species are mainly located in topographically induced anticyclonic eddies in areas under the influence of recent Atlantic water, near the Balearic frontal system (García et al., 2004; Fig. 1). Adults of these large pelagic migratory species could reach the Balearic archipelago by accompanying the surface Atlantic water and spawning could take place in these water masses.

A pronounced seasonal variability regarding both the number of species and the number of fish larvae in the plankton can be observed throughout the year. The two dominant species, sardine and anchovy, have long reproductive periods with completely opposite seasonal cycles, autumn-winter and springsummer respectively. The diversity of larval feeding patterns (Sabatés and Saiz, 2000; Fig. 2) as well as the succession of the reproductive activity of different fish species throughout the year might reduce inter- and intraspecific competition for food resources in this area.

During the winter, vertical mixing enhances productivity on continental shelves and maximum algal biomass and high primary productivity have been reported (Estrada et al., 1999). Nevertheless, only a few fish species reproduce: those fish

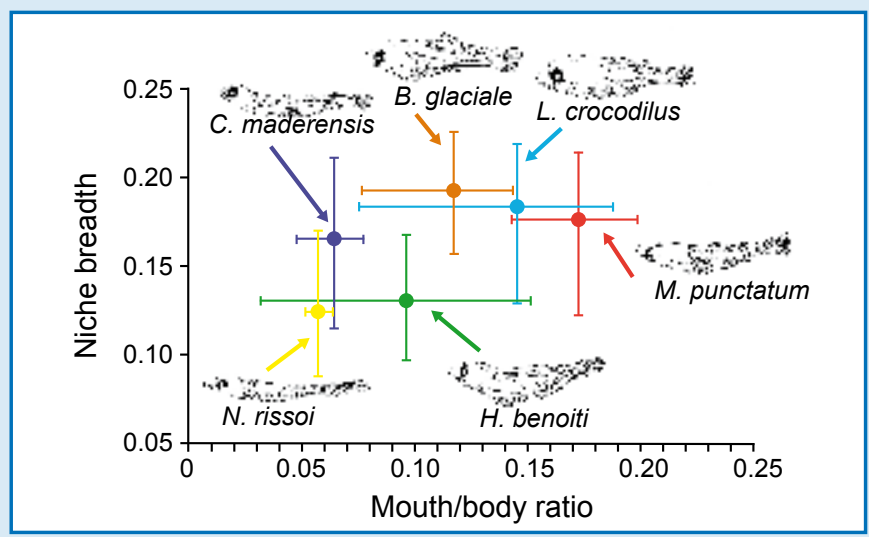

Figure 2. Relationship between mouth size: body size ratio and niche breadth (average of SD of log prey for each mouth-size class) for six Myctophiform fish larvae (Benthosema glaciale, Ceratoscopelus maderensis, Hygophum benoiti, Lampanyctus crocodilus, Myctophum punctatum, Notolepis rissoi).
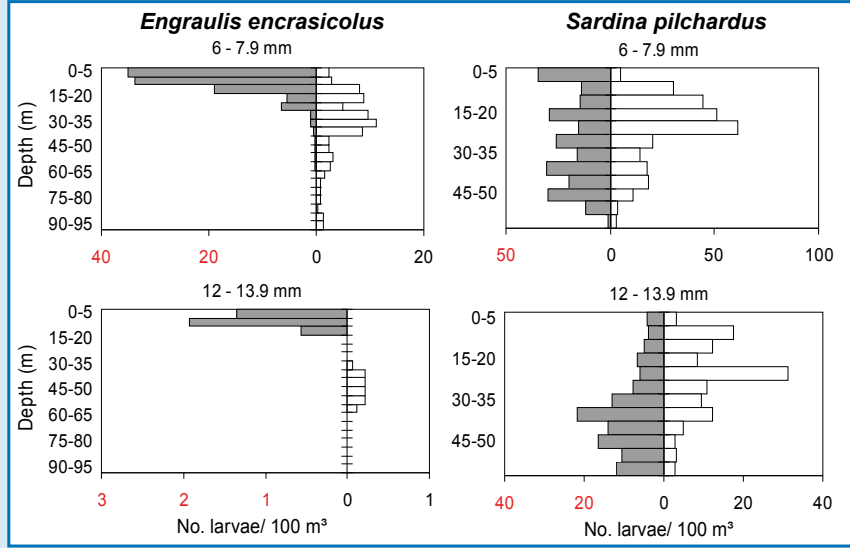

Figure 3. Vertical distribution of Engraulis encrasicolus and Sardina pilchardus larvae by size class, during the stratified and mixed period respectively. Daytime (light shading), night time (dark shading).

characteristic of relatively cold water, such as Sardina pilchardus, various species of Gadidae, Pleuronectidae and also some species of mesopelagic fish. Vertical vertical distribution of larval species that reproduce in this period is relatively wide (Fig. 3) due to the absence of vertical gradients, which involves a fairly uniform distribution of phytoplankton and microzooplankton in the upper layers. Moreover, there are no intense currents on the shelf and the circulation is usually anticyclonic, favouring larval retention in this zone. Most Mediterranean fish reproduce during the spring-summer stratified period, when the phytoplankton biomass values at the upper layers are lower than in winter. Thermocline development prevents vertical motion and nutrient supply to the surface is interrupted. Therefore, a deep chlorophyll maximum (DCM) can be found at the bottom of the photic zone. The development of the DCM and the high zooplankton biomass associated with it offers an important food source for fish larvae and high concentrations of larvae in advanced developmental states have been found close to the DCM (Olivar et al., 2001; Fig. 3). Additionally, during this period the inputs of continental waters are one of the fertilisation mechanisms of surface waters and some species, such as anchovy, take advantage of this situation. It is important to point out that during summer the cladocerans, which are very abundant in surface layers, make up a significant component in the diet of larvae of various fish species. In addition, during this period an important part of the larval fish diet comes directly from food items of protozoan origin. Calbet et al. (2002) suggested that during the summer, when densities of autotrophs are low, a significant part of the diet of zooplankton would be constituted by heterotrophs. Probably, in oligotrophic areas such as the Mediterranean this trophic link was of major importance resulting in a high efficiency of biomass and energy transfer from primary producers to higher trophic levels.

The variability in the spatio-temporal distribution patterns of larvae of different fish species can be explained by their coupling with the hydrodynamic processes and biological production associated with these. Fish species show reproductive strategies and larval fish behaviour that allow them to take advantage of the available resources throughout the seasonal cycle in an oligotrophic environment. These strategies, together with the high ecological efficiency of oligotrophic systems contribute to the relatively high yield of Mediterranean fisheries. 


\title{
References
}

Calbet A., E. Saiz and M. Alcaraz. 2002. Copepod egg production in the NW Mediterranean: Effects of winter environmental conditions. Marine Ecology Progress Series 237: 173-184.

Estrada M., R.A. Varela, J. Salat, A. Cruzado and E. Arias. 1999. Spatiotemporal variability of the winter phytoplankton distribution across the Catalan and North Balearic fronts (NW Mediterranean). Journal of Plankton Research 21: 1-20.

García A., F. Alemany, P. Velez-Belchí, J.L. López Jurado, D. Cortés, J.M. de la Serna, C. González Pola, J.M. Rodríguez, J. Jansá and T. Ramírez. 2004. Characterization of the bluefin tuna spawning habitat off the Balearic archipelago in relation to key hydrographic features and associated environmental conditions. Collective volume of scientific

papers, International Commission for the Conservation of Atlantic Tunas 58(2): 535-549.

Olivar M.P., J. Salat and I. Palomera. 2001. Comparative study of spatial distribution patterns of the early stages of anchovy and pilchard in the NW Mediterranean Sea. Marine Ecology Progress Series 217: 111-120.

Sabatés A. and E. Saiz. 2000. Intra- and interspecific variability in prey size and niche breadth of mesopelagic fish larvae. Marine Ecology Progress Series 201: 261-271.

Sabatés A., J. Salat and M. Masó. 2004. Spatial heterogeneity of fish larvae across a meandering current in the northwestern Mediterranean. Deep-Sea Research I 51: 545-557.

\section{Small pelagic fish in the NW Mediterranean Sea: an ecological review}

\author{
Isabel Palomera ${ }^{1}$, Maria Pilar Olivar ${ }^{1}$, Jordi Salat ${ }^{1}$, Ana Sabatés ${ }^{1}$, \\ Marta Coll ${ }^{1}$, Alberto García² and Beatriz Morales-Nin ${ }^{3}$ \\ ${ }^{1}$ Institut de Ciències del Mar (CSIC), Spain (isabel@icm.csic.es) \\ 2Instituto Español de Oceanografía, Centro Oceanográfico de Málaga, Spain \\ ${ }^{3}$ Institut Mediterrani d'Estudis Avançats (CSIC/UIB), Spain
}

In the NW Mediterranean Sea, anchovy (Engraulis encrasicolus) and sardine (Sardina pilchardus) are the most important small pelagic fish in terms of biomass and catch. Round sardinella (Sardinella aurita) and sprat (Sprattus sprattus) are also present in this region. A review of the information available on their biology and ecology has been done (Palomera et al., 2007) to point out the gaps in current knowledge necessary to understand the dynamics of small pelagic fish in the region and to progress towards a precautionary and adaptive management. The commercial exploitation of small pelagics in the NW Mediterranean has been significant since the early 1940s. Although sardine makes up the largest share, anchovy reaches a higher price in the market and is thus more important and subject to heavier fishing pressure.

Data obtained from different studies in the NW Mediterranean allowed us to characterise the spawning habitats of sardine, anchovy and round sardinella by temperature and salinity. Egg abundance superimposed on T-S plots (Fig. 1) clearly defines the spawning habitats of the three species based on water mass characteristics. Anchovy eggs in the region are mainly found in warm waters, between 17 and $23^{\circ} \mathrm{C}$, a temperature range that is located between that of the other two species. Moreover, anchovy is the only species that spawns in a wide salinity range, including waters of continental origin. Cold waters (12$14^{\circ} \mathrm{C}$ ) are preferred by sardine to spawn, although spawning also occurs up to $19^{\circ} \mathrm{C}$ (Fig. 1). The opposing trend is shown by round sardinella, which may spawn at an SST higher than $23^{\circ} \mathrm{C}$. The reproductive period of round sardinella in the NW Mediterranean stretches over the warmest period of the year, from July to October in accordance with its tropical origin.

According to their spawning periods, the increase in temperature and day length must trigger anchovy spawning, while the decrease in temperature and day length is the trigger in sardine. Nevertheless, the processes involved in the homogenisation of the water column and the considerable decrease in temperature are much more variable than those leading to the increase and stratification of the water column. This implies that the processes to reach optimum spawning conditions for sardine are longer and more variable than for anchovy. Larval distribution is also related to major productivity mechanisms of the respective spawning seasons. In spite of the different thermal regimes that anchovy and sardine experience during the early larval stages, growth rates for the two species are within similar ranges (Fig. 2). Taking into account that metabolic rates should be lower in colder waters, this suggests that other factors like food quality or assimilation efficiency could have a more important role as a compensatory factor in sardine larval growth processes.

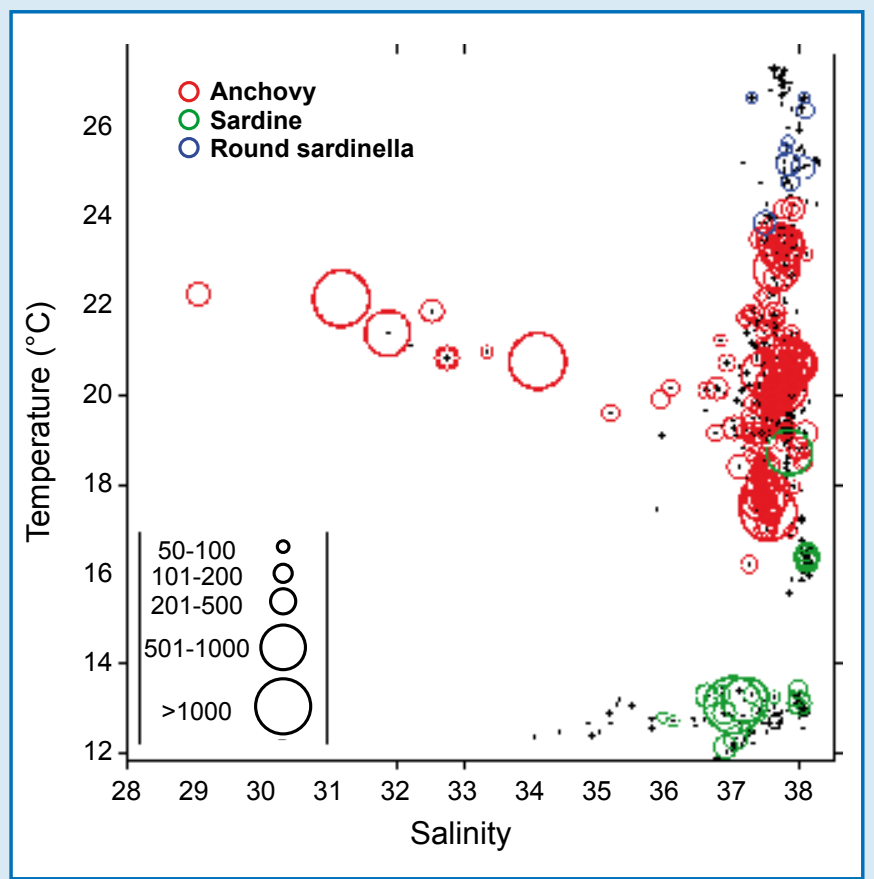

Figure 1. Surface temperature-salinity plots for anchovy, sardine and round sardinella eggs from surveys carried out in northwestern Mediterranean waters (only abundances $>50$ egg $\mathrm{m}^{-2}$ are drawn). 